\title{
QUALIDADE HIGIÊNICO-SANITÁRIA DE TAMBAQUI (Colossoma macropomum) COMERCIALIZADO NA CIDADE DE SÃO LUÍS - MA
}

\section{SANITARY HYGIENIC QUALITY OF TAMBAQUI (Colossoma macropomum) MARKETED IN THE CITY OF SÃO LUÍS - MA}

\author{
Eldo José R. dos Santos ${ }^{1 *}$ ORCID - http://orcid.org/0000-0001-8315-8804 \\ Lygia Silva Galeno ${ }^{1}$ ORCID - http://orcid.org/0000-0002-4431-7873 \\ Luciana da Silva Bastos ${ }^{1}$ ORCID - http://orcid.org/0000-0002-7916-9911 \\ Thaliane França Costa ${ }^{1}$ ORCID - http://orcid.org/0000-0002-9467-5847 \\ Isabel Azevedo Carvalho ${ }^{1}$ ORCID - http://orcid.org/0000-0002-8917-0692 \\ Francisca Neide Costa ${ }^{1}$ ORCID - http://orcid.org/0000-0002-8941-241X \\ ${ }^{1}$ Universidade Estadual do Maranhão, São Luiz, MA, Brasil. \\ *Autor para correspondência - eldojose10@hotmail.com
}

\section{Resumo}

A identificação das condições higiênico-sanitárias do pescado é de suma importância para a promoção da saúde e a qualidade de vida da população. Dessa forma, o presente trabalho teve como objetivo avaliar a qualidade microbiológica e verificar o perfil de susceptibilidade a antimicrobianos das cepas isoladas de amostras de tambaqui (C. macropomum) comercializadas na cidade de São Luís, Maranhão. As 60 amostras de tambaqui, obtidas de supermercados e feiras livres, foram analisadas quanto à determinação do Número Mais Provável (NMP) de coliformes totais e termotolerantes; pesquisa de Escherichia coli; pesquisa de Aeromonas spp., e perfil de resistência antimicrobiana. Foi detectada uma elevada contagem de coliformes totais e termotolerantes, além de bactérias patogênicas, tais como: Aeromonas spp. em 56 (93,3\%) e E. coli, em 13 (43,3\%) das amostras analisadas. Em relação ao perfil de resistência antimicrobiana, os isolados de E. coli demonstraram baixos percentuais de resistência e as cepas de Aeromonas apresentaram elevados níveis de resistência aos antimicrobianos testados. Pode-se concluir que o tambaqui comercializado em São Luís - MA apresenta condições higiênico-sanitárias inadequadas para o consumo.

Palavras-chave: microbiologia, pescado, saúde pública, antibiograma

\begin{abstract}
The identification of the hygienic-sanitary conditions of thTe fish is of is of the utmost importance for the promotion of health and life quality of the population, therefore the purpose of this study was to evaluate the microbiological quality and verify the susceptibility profile to antimicrobials of the isolated bacteria from tambaqui (C. macropomum) marketed in the city of São Luís, Maranhão. The 60 samples of tambaqui, obtained from supermarkets and free markets, were analyzed for the Most Probable Number (MPN) of total coliforms and thermotolerant; search for Escherichia coli; search for Aeromonas spp., and antimicrobial resistance profile. a high total coliform contagion and thermotolerant was detected, besides the presence of pathogenic bacteria, such as: Aeromonas spp. in $56(93.3 \%)$ and E. coli, in $13(43.3 \%)$ of the analyzed samples. Regarding the antimicrobial resistance
\end{abstract}


profile, the isolated of E. coli showed low percentages of resistance and Aeromonas strains had high levels of antimicrobial resistance tested. It can be concluded that the tambaqui marketed in São LuísMA presents hygienic-sanitary conditions that are inadequate for the consumer.

Key-Words: microbiology, fish, public health, antibiogram

Recebido em: 21 de abril de 2017.

Aceito em: 30 de novembro de 2018.

\section{Introdução}

O consumo de pescado no Brasil vem aumentando nos últimos anos, principalmente devido à grande preocupação com a saúde e à busca por dietas mais saudáveis ${ }^{(1)}$. Dentre as espécies de pescado mais consumidas no Brasil, destaca-se o tambaqui (Colossoma macropomum), peixe de água doce originário da América do Sul e presente em 24 estados brasileiros ${ }^{(2)}$.

Além de ser de fácil digestibilidade, esse alimento é rico em proteínas e aminoácidos essenciais, vitaminas, minerais e nutrientes solúveis em água, apresentando baixo teor de colesterol $^{(3)}$. Diversos estudos relatam os benefícios do consumo de pescado à saúde humana em mecanismos relacionados ao desenvolvimento fetal ${ }^{(4)}$ à e prevenção de hipertensão e doença cardiovascular, devido à presença de grande quantidade de lipídios que contêm elevadas taxas de ácidos graxos poli-insaturados ${ }^{(5)}$. Por essa razão, são recomendadas médias de consumo de $245 \mathrm{~g}$ de peixe por semana ${ }^{(6)}$.

Os produtos da pesca apresentam elevada taxa de perecibilidade em comparação com outros alimentos de origem animal, devido à presença de grande quantidade de água nos seus tecidos, $\mathrm{pH}$ próximo da neutralidade e acentuado teor de fosfolipídios e nutrientes. Tais fatores intensificam a multiplicação bacteriana que, na maioria das vezes, não altera a aparência do pescado, entretanto, decorre em patogenicidade ao homem ${ }^{(3)}$.

Dentre as bactérias patogênicas contaminantes do pescado, destacam-se Escherichia coli e Aeromonas spp., por causarem sérios riscos à saúde humana, mesmo em baixas quantidades nos alimentos $^{(7)}$. Entretanto, estudos que apontem dados sobre as gastroenterites provocadas por E. coli $\mathrm{e}$ Aeromonas na cidade de São Luís ainda são escassos. Ribeiro et al. ${ }^{(8)}$ avaliaram o uso de biomarcadores bioquímicos e análises microbiológicas para identificar níveis de contaminação de ostras em diferentes portos da Ilha de São Luís, identificando maior porcentagem de contaminação microbiológica durante a estação chuvosa.

Ressalta-se que, além desses agentes causadores de gastroenterite, outras bactérias e também protozoários e vírus representam um grave problema de saúde pública. No Brasil, os agentes etiológicos causadores de doença diarreica aguda de maior importância clínica e epidemiológica são: Salmonella spp., Shigella spp., Campylobacter jejuni e C. coli, Cryptosporidium spp., Entamoeba histolytica, Giardia lamblia e rotavírus. Contudo, a origem das bactérias responsáveis pela diarreia difere de acordo com a área geográfica e com os diferentes níveis de desenvolvimento econômico entre as regiões $(9,10,11,12,13)$.

Oliveira e Latorre ${ }^{(14)}$, avaliando as internações e a mortalidade infantil causadas por diarreia em menores de um ano de idade no Brasil, observaram que São Luís apresentou redução nas internações 
gerais de menores de um ano e na mortalidade infantil no período de 1995 a 2005, revelando a importância de medidas de prevenção e controle da doença e de seus agentes causadores, controlando a qualidade dos alimentos.

A manutenção da qualidade e da inocuidade do pescado é imprescindível para se obter um alimento seguro, havendo a necessidade de cuidados em todas as etapas da cadeia produtiva ${ }^{(15)}$. Visando à melhoria da qualidade dos produtos da pesca, deve-se ressaltar a importância do uso constante de boas práticas de manipulação, procedimentos-padrão de higienização e análise de perigos e pontos críticos de controle ${ }^{(16)}$.

Considerando a importância da identificação das condições higiênico-sanitárias do pescado, o presente trabalho teve como objetivo avaliar a qualidade microbiológica de tambaqui $(C$. macropomum) comercializado na cidade de São Luís, Maranhão, e verificar o perfil de susceptibilidade antimicrobiana das cepas bacterianas isoladas.

\section{Material e métodos}

As amostras de tambaqui (C. macropomum) foram obtidas nos principais supermercados e feiras livres que comercializam essa espécie de peixe na cidade de São Luís, no período de maio a agosto de 2016. Foram selecionados três supermercados, onde as amostras eram acondicionadas sobre camadas de gelo, e três feiras que comercializavam os peixes mantidos sobre o balcão em temperatura ambiente, dos quais foram coletadas 10 amostras de cada estabelecimento, totalizando 60 amostras. Cada amostra foi representada por $500 \mathrm{~g}$ de filé de peixe, acondicionadas e transportadas em caixa isotérmica para o Laboratório de Microbiologia de Alimentos e Água do Centro de Ciências Agrárias da Universidade Estadual do Maranhão - UEMA, onde foram analisadas.

Para as análises microbiológicas, foram preparados os filés de tambaqui (C. macropomum) sobre uma bandeja de inox previamente desinfetada com solução de álcool $70 \%$, para posteriormente serem pesadas e analisadas. O preparo e a análise das amostras foram realizados conforme a metodologia recomendada pela Instrução Normativa n ${ }^{\circ}$ 62, de 26 de agosto de 2003, do Ministério da Agricultura, Pecuária e Abastecimento, e do Manual de Métodos de Análise Microbiológica de Alimentos ${ }^{(17,18)}$.

$\mathrm{Na}$ pesquisa de E. coli, foram semeadas alíquotas de cada tubo positivo no caldo EC, em placas contendo Agar Eosina Azul de Metileno (EMB), que foram incubadas em estufa bacteriológica de $35^{\circ} \mathrm{C}$ por $24 \mathrm{~h}$. Após esse período, foram selecionadas de três a cinco colônias sugestivas (na cor azulescuro com brilho metálico) e transferidas para tubos de Ágar Tripticase Soja (TSA) inclinado, incubadas a $37^{\circ} \mathrm{C}$ por $24 \mathrm{~h}$. Em seguida, foram preparadas lâminas pelo método de Gram, para a verificação de sua morfologia. Após a constatação da presença de bacilos Gram-negativos, estes foram submetidos à confirmação bioquímica, na qual se realizaram os seguintes testes: produção de indol (I), Vermelho de metila (MV), Voges-Proskauer (VP) e do citrato (C), segundo a técnica descrita por Vanderzant \& Splittsoesser ${ }^{(19)}$.

Para a pesquisa de Aeromonas spp., foi utilizada metodologia descrita por Palumbo et al. ${ }^{(19)}$, Majeed et al. ${ }^{(20)}$ e Havelaar \& Vonk ${ }^{(21)}$. De cada amostra, foram transferidos $25 \mathrm{~g}$ para $225 \mathrm{~mL}$ de caldo tripcase de soja (TSB), adicionado de ampicilina $(30 \mathrm{mg} / \mathrm{L})$, que foi incubado a $28^{\circ} \mathrm{C}$ por $24 \mathrm{~h}$. Em seguida, foi realizada a semeadura para placas contendo agar dextrina-ampicilina (ADA) e agar 
vermelho de fenol amido-ampicilina (AVF), incubados a $28^{\circ} \mathrm{C}$ por 24 horas. As colônias suspeitas foram incubadas em agar TSA a $28^{\circ} \mathrm{C}$ por 24 horas. Na sequência, foram realizados os seguintes testes bioquímicos: prova de catalase e oxidase para a caracterização do gênero ${ }^{(22)}$ e, para a identificação das espécies, foram realizadas provas bioquímicas, segundo a chave de identificação Aerokey II ${ }^{(23)}$.

O teste de sensibilidade e de resistência aos antimicrobianos foi realizado pelo método de difusão em discos ${ }^{(24)}$. Foram utilizados os seguintes discos de antimicrobianos: ampicilina $(10 \mu \mathrm{g})$, amicacina $(30 \mu \mathrm{g})$, amoxicilina clavulanato $(30 \mu \mathrm{g})$, gentamicina $(10 \mu \mathrm{g})$, cefuroxima $(30 \mu \mathrm{g})$, cefepime $(30 \mu \mathrm{g})$, cefoxitina $(30 \mu \mathrm{g})$, cefotaxima $(30 \mu \mathrm{g})$, ciprofloxacin $(5 \mu \mathrm{g})$, piperaciclina $(110 \mu \mathrm{g})$, sulfa trimetoprin $(25 \mu \mathrm{g})$. Os halos formados pelos discos de antimicrobianos foram mensurados com régua e interpretados de acordo com a tabela-padrão para testes de susceptibilidade a antimicrobianos e classificados como resistentes, intermediários ou sensíveis ${ }^{(25)}$.

Para a análise estatística dos resultados, foi utilizado o programa GraphPad Prism 6 (GraphPad Software Inc., San Diego, CA, EUA), pelo qual os dados foram analisados através do teste t (não pareado) para descrição das amostras de peixe contaminadas. Para a comparação das médias dos resultados obtidos em feiras e supermercados, utilizou-se o teste one-way ANOVA. Os resultados foram considerados significativos quando houve significância superior a $95 \%(\mathrm{p}<0,05)^{(26)}$.

\section{Resultados e discussão}

Na Tabela 1, estão descritos os resultados das análises microbiológicas nas amostras de filés de tambaqui (C. macropomum) provenientes de feiras (30 amostras) e supermercados (30 amostras).

Tabela 1. Número e percentual de contaminação por coliformes totais e termotolerantes e presença $E$. coli e Aeromonas spp. em 60 amostras de filés de tambaqui $(C$. macropormum) comercializadas em feiras e supermercados da cidade de São Luís, MA, 2016

\begin{tabular}{|c|c|c|c|c|c|c|c|c|}
\hline \multirow{3}{*}{$\begin{array}{c}\text { Micro- } \\
\text { organismos }\end{array}$} & \multicolumn{8}{|c|}{ Filés de Tambaqui } \\
\hline & \multicolumn{4}{|c|}{ Feiras } & \multicolumn{4}{|c|}{ Supermercados } \\
\hline & $\mathbf{N}$ & N.A.C. & $\%$ & Média/DP & $\mathbf{N}$ & N.A.C. & $\%$ & Média/DP \\
\hline $\begin{array}{l}\text { Coliformes } \\
\text { totais (NMP/g) }\end{array}$ & 30 & 29 & 96,7 & $9,7^{*} \pm 0,3$ & 30 & 19 & 63,3 & $6,3 \pm 1,8$ \\
\hline $\begin{array}{l}\text { Coliformes } \\
\text { termotolerantes } \\
(\mathrm{NMP} / \mathrm{g})\end{array}$ & 30 & 25 & 83,3 & $8,3^{*} \pm 1,2$ & 30 & 7 & 23,3 & $2,3 \pm 0,7$ \\
\hline Escherichia coli & 30 & 13 & 43,3 & $4,3^{*} \pm 1,2$ & 30 & 0 & 0,0 & $0,0 \pm 0,0$ \\
\hline Aeromonas spp. & 30 & 30 & 100,0 & $10,0 \pm 0,0$ & 30 & 26 & 86,7 & $8,7 \pm 0,3$ \\
\hline
\end{tabular}


Tanto para coliformes como para a presença de E. coli, a contaminação de peixes comercializados em feiras se mostrou estatisticamente superior à de supermercados (Tabela 2). Nas amostras obtidas em feiras, foi observada presença de coliformes totais em $29(96,7 \%)$ das amostras analisadas e, para coliformes termotolerantes, foi verificada contaminação em 25 (83,3\%). Das amostras obtidas em supermercados, $19(63,3 \%)$ apresentaram coliformes totais e, em $7(23,3 \%)$, foi verificada a presença de coliformes termotolerantes.

Foi detectada a presença da bactéria E. coli em $13(43,3 \%)$ das amostras analisadas, todas provenientes de peixes comercializados nas feiras livres. Embora a legislação não tenha ainda estabelecido um padrão para a presença desse microrganismo em pescado in natura, esses dados servem para alertar os órgãos fiscalizadores sobre o aspecto higiênico-sanitário do pescado, como está sendo capturado e manipulado para o consumo humano.

Segundo Doi et al. ${ }^{(27)}$, a presença de E. coli no alimento representa em grandes escalas a presença de matéria fecal, pois esse microrganismo tem como habitat natural o trato intestinal do homem e de vários outros animais homeotérmicos. Nos estabelecimentos que comercializam essa espécie em feiras da cidade de São Luís - MA, foi observada a falta de higiene em todas as etapas de comercialização, além do manuseio do alimento de forma inadequada, presença de animais no local e armazenamento inadequado.

Pode-se observar (Tabela 2) que houve maior número de amostras contaminadas por coliformes totais e a $45^{\circ} \mathrm{C}$ nos exemplares provenientes das feiras do que dos supermercados, com valores que chegaram a $\geq 1100 \mathrm{NMP} / \mathrm{g}$. Lorezon et al. ${ }^{(28)}$ também encontraram coliformes totais e coliformes termotolerantes em peixes de cultivo, com valores máximos de $10^{4} \mathrm{NMP} / \mathrm{g}$ de e $10^{3} \mathrm{NMP} / \mathrm{g}$ respectivamente. A RDC 12 (BRASIL) não dispõe de padrões para coliformes totais e a $45^{\circ} \mathrm{C}$ para pescado em natureza. Essa resolução estabelece que produtos à base de pescado resfriado ou congelados possam ter um limite tolerável de $10^{3} \mathrm{NMP} / \mathrm{g}$ para esses micro-organismos. Deste modo, por similaridade, quando se comparam os resultados obtidos nas feiras livres com o padrão recomendado para produtos à base de pescado resfriado, pode-se caracterizar que as amostras de peixe foram obtidas em ambiente que propicia falhas que comprometem a qualidade higiênicosanitária.

Tabela 2. Variação mínima e máxima do Número Mais Provável de coliformes totais e termotolerantes em 60 amostras de filés de tambaqui (C. macropomum), comercializadas em feiras e supermercados da cidade de São Luís, MA, 2016

\begin{tabular}{|c|c|c|c|c|c|c|c|c|}
\hline \multirow{3}{*}{ NMP/g } & \multicolumn{4}{|c|}{ Coliformes totais } & \multicolumn{4}{|c|}{ Coliformes termotolerantes } \\
\hline & \multicolumn{2}{|c|}{ Feiras } & \multicolumn{2}{|c|}{ Supermercados } & \multicolumn{2}{|c|}{ Feiras } & \multicolumn{2}{|c|}{ Supermercados } \\
\hline & $\mathbf{N}$ & $\%$ & $\mathbf{N}$ & $\%$ & $\mathbf{N}$ & $\%$ & $\mathbf{N}$ & $\%$ \\
\hline$<3$ & 01 & 3,3 & 11 & 36,7 & 05 & 16,7 & 23 & 76,7 \\
\hline 3 a 460 & 17 & 56,7 & 16 & 53,3 & 17 & 56,7 & 06 & 20,0 \\
\hline$\geq 1100$ & 12 & 40,0 & 03 & 10,0 & 08 & 26,7 & 01 & 3,3 \\
\hline TOTAL & 30 & $100 \%$ & 30 & $100 \%$ & 30 & $100 \%$ & 30 & $100 \%$ \\
\hline
\end{tabular}


Elevadas contagens de coliformes e de bactérias como E. coli estão relacionadas, principalmente, às condições precárias de higiene desse alimento no seu local de comercialização. O grande número de coliformes totais observado nas análises desses peixes é um indicativo da qualidade higiênicosanitária, além de fornecer informações sobre o grau de contaminação ao qual está sendo exposto esse alimento. De acordo com o que foi observado, os supermercados são os estabelecimentos que estão mais próximos de um padrão desejado, visto que houve baixa contagem de coliformes e ausência de E. coli.

No entanto, mesmo atendendo a alguns requisitos de manipulação de peixes, os supermercados ainda carecem de melhorias no processo de manipulação e de armazenamento desse alimento. Embora haja menor contaminação no tambaqui proveniente de supermercados, pode ocorrer contaminação cruzada, principalmente pelo gelo utilizado nesses estabelecimentos. Lopes et al., ${ }^{(29)}$ ao analisarem a qualidade microbiológica de gelo proveniente de fábricas localizadas em Cedral, MA, destacaram que a presença de coliformes em amostras de pescados, embora em baixas concentrações, pode ser decorrente da contaminação do gelo utilizado durante a conservação do produto, além de outras fontes de contaminação durante o manuseio desse alimento.

Quanto aos resultados da pesquisa de bactérias do gênero Aeromonas, do total de 60 amostras analisadas, $56(93,3 \%)$ estavam contaminadas com a presença desse gênero bacteriano. Destas, foram isoladas cinco espécies (Tabela 3). Estavam contaminadas por Aeromonas 30 (100\%) amostras obtidas em feiras livres e $26(86,6 \%)$ das 30 amostras de supermercados.

Tabela 3. Número de amostras contaminadas por espécies de Aeromonas isoladas de 60 amostras filés de tambaqui (C. macropomum) coletadas em supermercados e feiras livres da cidade de São Luís, MA, 2016

\begin{tabular}{lcc}
\hline Espécie de Aeromonas isolada & Número de amostras & $\%$ \\
\hline A. hydrophila & 47 & 83,9 \\
A. veronii biovar veronii & 4 & 7,1 \\
A. caviae & 3 & 5,4 \\
A. trota & 1 & 1,8 \\
A. schubertii & 1 & 1,8 \\
\hline Total & 56 & 100,0 \\
\hline
\end{tabular}

A elevada ocorrência da presença de Aeromonas no estudo está de acordo com outras pesquisas envolvendo peixes ou produtos do pescado. Esses achados são corroborados pelos de Silva et al. ${ }^{(30)}$, que, ao analisarem 48 amostras de água de viveiros na região da Baixada Ocidental Maranhense, confirmaram a presença de Aeromonas spp. em todas as amostras analisadas. Outras pesquisas destacam a presença desses microrganismos no ambiente aquático, especialmente em água doce ${ }^{(31,32)}$. Este fato pode explicar o elevado índice de amostras contaminadas por esse patógeno, além de possível contaminação cruzada em toda a sua cadeia de distribuição.

Das cinco espécies de Aermonas identificadas, merece destaque a espécie A. hydrophila, pois frequentemente está associada à deterioração do pescado, além de ser de grande importância para a saúde pública. Segundo Peixoto et al. ${ }^{(33)}$, espécies de A. hydrophila estão entre as cinco de grande relevância clínica, principalmente por serem patogênicas para os peixes e também para os seres humanos e por terem capacidade de produzir exotoxinas. 
Segundo Figueira et al. ${ }^{(34)}$, peixes e outros frutos do mar podem se tornar fontes de contaminação para seres humanos devido ao fato de algumas vezes abrigarem espécies potencialmente patogênicas como, A. hydrophila, A. sobria, A. caviae e A. media.

De acordo com a Tabela 3, outras espécies de Aeromonas foram encontradas em menor quantidade nas amostras de tambaqui. Isso pode ser explicado pelo fato de bactérias do gênero Aeromonas spp. fazerem parte da microbiota autóctone de ecossistemas aquáticos, tanto de água doce como de água salgada, podendo sobreviver nas mais diversas faixas de temperaturas. Com isso também se explica a ausência de diferença significativa entre as amostras provenientes de feiras e supermercados quanto à presença de Aeromonas, conforme é mostrado na Tabela 1.

Quanto à susceptibilidade aos antimicrobianos (Tabela 4) nas cepas de E. coli isoladas das amostras de tambaqui (C. macropomum) comercializadas na cidade de São Luís - MA, verificam-se elevados percentuais de sensibilidade em nove dos 11 antimicrobianos testados. No presente estudo, foram verificados que $84,6 \%$ das cepas testadas apresentaram resistência à gentamicina e apenas 7,6\% apresentaram resistência a cefotaxima, ou seja, apenas dois dos 11 antimicrobianos testados. Em casos de infecções causadas por esse micro-organismo, esses antibióticos não seriam recomendados para um provável tratamento.

Tabela 4. Susceptibilidade a antimicrobianos de cepas de E. coli isoladas de amostras de filé de tambaqui (C. macropomum) comercializadas em São Luís - MA, 2016

\begin{tabular}{lcccc}
\hline \multirow{2}{*}{ Antimicrobianos } & \multicolumn{4}{c}{ Numero de cepas } \\
\cline { 2 - 5 } & Resistente \% & Intermediário \% & Sensivel \% & Total \\
\hline Ampicilina & 0 & 0 & $13(100 \%)$ & $\mathbf{1 3}$ \\
Amicacina & 0 & $2(15,3 \%)$ & $11(84,6 \%)$ & $\mathbf{1 3}$ \\
Amoxicilina Clavulanato & 0 & 0 & $13(100 \%)$ & $\mathbf{1 3}$ \\
Gentamicina & $11(84,6 \%)$ & $1(7,6 \%)$ & $1(7,6 \%)$ & $\mathbf{1 3}$ \\
Cefuroxima & 0 & $10(76,9 \%)$ & $3(23 \%)$ & $\mathbf{1 3}$ \\
Cefepime & 0 & 0 & $13(100 \%)$ & $\mathbf{1 3}$ \\
Cefoxitina & 0 & 0 & $13(100 \%)$ & $\mathbf{1 3}$ \\
Cefotaxima & $1(7,6 \%)$ & 0 & $12(92,3 \%)$ & $\mathbf{1 3}$ \\
Ciprofloxacina & 0 & 0 & $13(100 \%)$ & $\mathbf{1 3}$ \\
Piperacilina & 0 & $2(15,3 \%)$ & $11(84,6 \%)$ & $\mathbf{1 3}$ \\
Sulfa Trimetropin & 0 & 0 & $13(100 \%)$ & $\mathbf{1 3}$ \\
\hline
\end{tabular}

As cepas isoladas apresentaram $100 \%$ de sensibilidade a ampicilina, amoxicilina clavulanato, cefepime, cefoxitina, ciprofloxacina e sulfa trimetoprim. Além destes, verificou-se sensibilidade de $92,3 \%$ para cefotaxima e $84,6 \%$ para amicacina e piperaciclina. Assim, estes são os antimicrobianos de eleição para o tratamento de infecções causadas por essa bactéria.

Além disso, as cepas isoladas mostraram percentuais de resistência intermediária para quatro dos antimicrobianos testados. Sob o entendimento clínico, essas bactérias seriam consideradas resistentes, o que diminui as opções de tratamento para pacientes acometidos com doenças relacionadas às bactérias analisadas neste estudo ${ }^{(30)}$.

Resultados semelhantes foram encontrados por Dias et al. ${ }^{(35)}$, que, ao avaliarem 44 cepas de E. coli 
isoladas de amostras cárneas de mexilhões capturados no município de Niterói, estado do Rio de Janeiro, verificaram uma resistência de apenas 4,16\% dos 24 antimicrobianos testados e uma elevada sensibilidade a estes. No estudo de Evangelista-Barreto et al. ${ }^{(36)}$, nenhuma das cepas de E. coli isoladas de amostras de ostras e sururus da Baía do Iguapé, Maragogipe (BA), apresentou resistência aos antimicrobianos amicacina e ciprofloxacina. Dados estes que mostram uma significância aceitável no uso desses antimicrobianos para tratamentos de infecções causadas por essa bactéria.

Embora vários estudos apontem a resistência aos antimicrobianos como um aumento considerável, no entanto, são ações como simples manejo higiênico-sanitário adequado que cada vez mais são relatadas como formas eficientes de se prevenir as doenças e possivelmente contribuir para uma acentuada diminuição na resistência bacteriana a esses antimicrobianos.

Na Tabela 5, observa-se que, de um modo geral, as cepas isoladas de Aeromonas spp., oriundas de tambaqui (C. macropomum), comercializados em feiras e supermercados da cidade de São Luís, apresentaram elevados percentuais de resistência aos 11 antimicrobianos testados, sendo que cinco estavam acima de $50 \%$.

Tabela 5. Susceptibilidade a antimicrobianos de cepas de Aeromonas spp. isoladas de amostras de tambaqui (C. macropomum) comercializado em São Luís - MA, 2016

\begin{tabular}{lcccc}
\hline \multirow{2}{*}{ Antimicrobianos } & \multicolumn{4}{c}{ Numero de cepas } \\
\cline { 2 - 5 } & Resistente & Intermediário & Sensível & Total \\
\hline Ampicilina & $55(98,2 \%)$ & $1(1,7 \%)$ & 0 & $\mathbf{5 6}$ \\
Amicacina & $9(16 \%)$ & $8(14,2 \%)$ & $39(69,6 \%)$ & $\mathbf{5 6}$ \\
Amoxicilina Clavulanato & $52(92,8 \%)$ & $3(5,3 \%)$ & $1(1,7 \%)$ & $\mathbf{5 6}$ \\
Gentamicina & $3(5,3 \%)$ & $6(10,7 \%)$ & $47(83,9 \%)$ & $\mathbf{5 6}$ \\
Cefuroxima & $52(92,8 \%)$ & $4(7,1 \%)$ & 0 & $\mathbf{5 6}$ \\
Cefepime & $3(5,3 \%)$ & $1(1,7 \%)$ & $52(92,8 \%)$ & $\mathbf{5 6}$ \\
Cefoxitina & $51(91 \%)$ & $1(1,7 \%)$ & $4(7,1 \%)$ & $\mathbf{5 6}$ \\
Cefotaxima & $36(64,2 \%)$ & $7(12,5 \%)$ & $13(23,2 \%)$ & $\mathbf{5 6}$ \\
Ciprofloxacina & $8(14,2)$ & $7(12,5 \%)$ & $41(73,2)$ & $\mathbf{5 6}$ \\
Piperaciclina & $4(7,1 \%)$ & $1(1,7 \%)$ & $51(91 \%)$ & $\mathbf{5 6}$ \\
Sulfa Trimetoprim & $23(41 \%)$ & $3(5,3 \%)$ & $30(53,5 \%)$ & $\mathbf{5 6}$ \\
\hline
\end{tabular}

Observa-se que 55 isolados apresentaram resistência à ampicilina, 52 à amoxicilina clavulanato e à cefuroxima, 51 à cefoxitina, 36 à cefotaxima, 23 à sulfa trimetoprim, 9 à amicacina, 8 à ciprofloxacina, 4 à piperaciclina e 3 à gentamicina e à cefepime. Além disso, mostraram percentuais de sensibilidade bastante significativos, em seis dos antimicrobianos testados com valores acima de $50 \%$ e, para perfis intermediários, apresentaram baixos percentuais.

Essa elevada resistência de cepas de Aeromonas spp. isoladas de tambaqui à ampicilina neste estudo está de acordo com pesquisa realizada por Silva et $\mathrm{al}^{(30)}$, que, ao analisarem cepas de Aeromonas spp. isoladas de peixes oriundos de pisciculturas da região da Baixada Ocidental Maranhense, observaram que todas as amostras apresentaram resistência à ampicilina. Segundo Ghenghesh et al. ${ }^{(37)}$, a grande maioria das espécies de Aeromonas spp. apresenta resistência à ampicilina, sendo esse antimicrobiano utilizado nos meios de cultura seletivo para isolamento desse microrganismo.

Além de elevada resistência à ampicilina $(98,2 \%)$, foram observadas elevada resistência a amoxicilina clavulanato e cefuroxima $(92,8 \%)$, cefoxitina $(91 \%)$ e cefotaxima $(64,2 \%)$. Silva et al. ${ }^{(30)}$ encontraram 
valores de $89,9 \%$ e 78,6\% de cepas de Aeromonas spp. resistentes à amoxicilina clavulanato e à cefuroxima, respectivamente. A resistência antimicrobiana para a cefoxitina também foi observada por Cereser et al. ${ }^{(38)}$, com percentual de $75 \%$ das de Aeromonas spp. isoladas, resultado bem próximo ao do presente estudo. Segundo Jacobs \& Chenia ${ }^{(39)}$, a resistência de Aeromonas spp. aos $\beta$ lactâmicos (ampicilina e amoxicilina) é explicada, pois estas são produtoras naturais de $\beta$-lactamase ou induzem sua atividade enzimática, rompendo a estrutura molecular desses antibióticos ${ }^{(40)}$.

Os antimicrobianos nos quais as bactérias evidenciaram menores percentuais de resistência foram amicacina (16\%), gentamicina e cefepime $(5,3 \%)$ ciprofloxacina $(14,2 \%)$ e piperaciclina $(7,1 \%)$. Portanto, em caso de enfermidades causadas por esse microrganismo, estes são os antimicrobianos de eleição para o tratamento das infecções. Os dados obtidos no presente estudo servem como grandes ferramentas para a escolha correta do princípio ativo a ser prescrito para tratamento.

Akinbowale et al. ${ }^{(31)}$ também verificaram baixa resistência de Aeromonas spp. a ciprofloxacina, ao analisarem amostras de trutas provenientes de pisciculturas. Silva et al. ${ }^{(30)}$ verificaram pouca resistência desses microrganismos em relação à gentamicina e à ciprofloxacina, em 14,9\% e 19,14\%, respectivamente.

Uma limitação importante desta pesquisa é a falta de informações relativa à utilização e à frequência de aplicação de antimicrobianos, visto que as amostras foram coletadas em feiras livres e supermercados e a informação que se tem é que a origem desse peixe, na sua maioria, é proveniente de criadores locais e regionais. Porém, foi observado um elevado percentual de resistência aos mais variados tipos de antimicrobianos, sugerindo que é feita a utilização de antibióticos na piscicultura e estes provocam resistência às bactérias presentes no meio, especialmente as do gênero Aeromonas, conforme verificados na presente pesquisa. Existe grande variabilidade gênica entre as populações bacterianas, o que garante diversidade na sensibilidade a determinado antimicrobiano ${ }^{(35)}$.

\section{Conclusões}

O tambaqui (C. macropomum), comercializado em feiras e supermercados da cidade de São Luís MA, apresenta condições higiênico-sanitárias insatisfatórias e pode veicular, para os consumidores dessa espécie de peixe, bactérias patogênicas como E. coli e Aeromonas spp, principalmente A. hydrophila, com consideráveis percentuais de resistência a antimicrobianos. Assim, para garantir a inocuidade do pescado, são necessários a monitorização dos padrões exigidos pela legislação e o adequado controle de qualidade do alimento.

\section{Agradecimentos}

À CAPES pela concessão da bolsa de estudo, à FAPEMA pelo financiamento da pesquisa por meio do Edital Universal $n^{\circ}$ 40/2014, à UEMA e ao Mestrado em Ciência Animal por serem os responsáveis pela minha formação profissional. 


\section{Referências}

1. Tayel AA. Microbial chitosan as a biopreservative for fish sausages. International Journal of Biological Macromolecules. 2016;93:41-46.

2. Lopera-Barrero NM, Ribeiro RP, Povh JA, Vargas LDM, Poveda-Parra AR, Digmayer M. As principais espécies produzidas no Brasil. In: Lopera-Barrero NM, Ribeiro RP, Povh JA, Vargas LDM, Poveda-Parra AR, Digmayer M, organizadores. Produção de organismos aquáticos: uma visão geral no Brasil e no mundo. Guaíba: Agrolivros; 2011;143-215.

3. Soares KMP, Goncalves AA. Qualidade e segurança do pescado. Revista Instituto Adolfo Lutz (Impr.). 2012; 71(1):1-10.

4. Carwile JL, Butler LJ, Janulewicz PA, Winter MR, Aschengrau A. Childhood Fish Consumption and Learning and Behavioral Disorders. International Journal of Environmental Research and Public Health, 2016;13(11):1069.

5. Burger J, Gochfeld M, Batang Z, Alikunhi N, Al-Jahdali, R. Fish consumption behavior and rates in native and non-native people in Saudi Arabia. Environmental Research, 2014;133:141-148.

6. Thurstan RH, Roberts CM. The past and future of fish consumption: Can supplies meet healthy eating recommendations? Marine Pollution Bulletin. 2014;89:5-11.

7. Greig JD, Ravel A. Analysis of foodborne outbreak data reported internationally for source attribution. International Journal of Food Microbiology 2009;130:77-87.

8. Ribeiro EB, Bastos LS, Galeno LS, Mendes RS, Garinojr F, Carvalho-Neta RNF, Costa FN. Integrated assessment of biomarker responses and microbiological analysis of oysters from São Luís Island, Brazil. Marine Pollution Bulletin, 2016;113(1-2):182-186.

9. Loureiro ECB, Souza CO, Sousa EB, Santos DV, Rocha DCC, Ramos FLP, Silva MCM. Detecção de bactérias enteropatogênicas e enteroparasitas em pacientes com diarreia aguda em Juruti, Pará, Brasil. Revista Pan-Amazônica de Saude. 2010;1(1):143-8.

10. Bicer S, Col D, Erdag GC, Giray T, Gurol Y, Yilmaz G, Vitrinel A, Ozelgun B. A retrospective analysis of acute gastroenteritis agents in children admitted to a university hospital pediatric emergency unit. Jundishapur Journal of Microbiology. 2014;7(4):e9148.

11. Vasco G, Trueba G, Atherton R, Calvopiña M, Cevallos W, Andrade T, Eguiguren M, Eisenberg JN. Identifying etiological agents causing diarrhea in low income Ecuadorian communities. The American Journal of Tropical Medicine and Hygiene. 2014;91(3):563-569.

12. Sánchez-Capilla AD, Sorlózano-Puerto A, Rodríguezgranger J, Martínez-Brocal A, Navarro-Marí JM, Gutiérrez-Fernández J. Infectious etiology of diarrheas studied in a third-level hospital during a five-year period. Revista Española de Enfermedades Digestivas. 2015;107(2):89-97.

13. Wang X, Wang J, Sun H, Xia S, Duan R, Liang J, Xiao Y, Qiu H, Shan G, Jing H. Etiology of childhood infectious diarrhea in a developed region of China: compared to childhood diarrhea in a developing region and adult diarrhea in a developed region. PLoS One. 2015;10(11):e0142136.

14. Oliveira TCR, Latorre MRDO. Tendências da internação e da mortalidade infantil por diarréia: Brasil, 1995 a 2005. Revista de Saúde Pública. 2010;44(1):102-11.

15. Cicero LH, Furlan EF, Prisco RCB, Neiva CRP. Estudo das metodologias de destilação na quantificação do Nitrogênio das Bases Voláteis Totais em pescada, tilápia e camarão. Brazilian Journal of Food Technology. 
2014;17(3):192-197.

16. Duarte AR, Ribeiro AMM, Vasconcelos JVD, Silva PLA, Santana AAP. Ocorrência de Salmonella spp. e Staphylococcus coagulase positiva em pescado no nordeste, Brasil. Arquivos do Instituto Biológico.2010;77(4):711-713.

17. Silva N, Junqueira VCA, Silveira NFA, Taniwaki MH, Santos RFS, Gomes RAR. Manual de métodos de análise microbiológica de alimentos. 3.ed. São Paulo: Varela, 2007. 536 p.

18. BRASIL. Ministério da Agricultura, Pecuária e Abastecimento. Instrução Normativa n.62, 26 de agosto de 2003. Oficializa os Métodos Analíticos Oficiais para Análises Microbiológicas para Controle de Produtos de Origem Animal e Água. Diário Oficial da União, de 18 de setembro de 2003. Seção I, p.14.

19. Palumbo SA, Maxino F, Williams AC, Buchanan RL, Thayer DW. Starch-ampicilin Ágar for the quantitative detection of Aeromonas hydrophila. Applied and Environmental Microbiology. 1985;50:10271030.

20. Majeed KN, Egan AF, Macera IC. Production of exotoxins by Aeromonas spp. at $5^{\circ} \mathrm{C}$. Journal of Applied Microbiology. 1990;69:332-337.

21. Havelaar AH, Vonk M. The preparation of ampicillin dextrin Ágar for the enumeration of Aeromonas in water. Letters in Applied Microbiology. 1988;7(6):169-171.

22. Saad SMI, Iaria ST, Furlaneto SM. Motile Aeromonas spp. in retail vegetables from São Paulo, Brazil. Revista de Microbiologia. 1995;26(1):22-27.

23. Carnahan AM, Behram S, Joseph SW. Aerokey II: a flexible key for identifying clinical Aeromonas species. Journal of Clinical Microbiology. 1991;29:2843-2849.

24. Bauer AW, Kirk MM, Sherris JC. Antibiotic susceptibility testing by a standardized single disk method. American Journal of Clinical Pathology. 1966;45:493-496.

25. CLSI publication M100-S23 Suggested Grouping of US-FDA Approved Antimicrobial Agents That Should Be Considered for Routine Testing and Reporting on Nonfastidious Organisms by Clinical Laboratories, 2013.

26. Sampaio IBM. Estatística aplicada à experimentação animal. Belo Horizonte: Fundação de Ensino e Pesquisa em Medicina Veterinária e Zootecnia, 1998. 221p.

27. Doi AS, Oliveira AJFC, Barbieri, E. Determinação de coliformes na água e no tecido mole das ostras extraídas em Cananéia, São Paulo, Brasil. Engenharia Sanitária Ambiental. 2015;20(1):111-118.

28. Lorenzon CS, Gatti Junior P, Nunes AP, Pinto FR, Scholten C, Honda SN.; et al. Perfil microbiológico de peixes e água de cultivo em pesque-pagues situados na região nordeste do Estado de São Paulo. Revista Arquivos do Instituto Biológico. 2010;77(4):617-624.

29. Lopes IS, Ferreira EM, Pereira DM, Pereira LS, Cunha MCS, Costa FN. Pescada amarela (Cynoscion acoupa) desembarcada: características microbiológicas e qualidade do gelo utilizado na sua conservação. Revista Instituto Adolfo Lutz. 2012;71(4):677-684.

30. Silva RML, Rossi-Junior OD, Costa FN, Chaves NP, Nascimento DL, Kamimura, BA. Aeromonas spp. em água de pisciculturas da região da baixada ocidental maranhense. Boletim do Instituto de Pesca. 2010;36(3):245 - 249 .

31. Akinbowale OL, Peng H, Grant P, Barton MD. Antibiotic resistance in motile aeromonads and pseudomonads from rainbow trout (Oncorhynchus mykiss) farms in Australia. International Journal of Antimicrobial Agents. 2007;30:177-182. 
32. Praveen PK, Debnath C, Shekhar S, Dalai N, Ganguly S. Incidence of Aeromonas spp. infection in fish and chicken meat and its related public health hazards: A review. Veterinary World. 2016;9(1):6-11.

33. Peixoto LJS, Sá MCA, Gordiano LA, Costa MM. Aeromonas spp.: fatores de virulência e perfis de resistência a antimicrobianos e metais pesados. Revista Arquivos do Instituto Biológico. 2012;79(3):453-461.

34. Figueira VM, Silva M, Manaia CM. Diversity and antibiotic resistance of Aeromonas spp. In drinking and waste water treatment plants. Water Research. 2011;45(17):5599-5611.

35. Dias MT, Santos PCRF, Oliveira LAT, Marin VA. Avaliação da sensibilidade de cepas de Escherichia coli isoladas de mexilhões (Perna perna Linnaeus, 1758) à antimicrobianos. Ciência e Tecnologia de Alimentos. 2010;30(2):319-324.

36. Evangelista-Barreto NS, Pereira AF, Silva RAR, Ferreira LTB. Presença de enteropatógenos resistentes a antimicrobianos em ostras e sururus da Baía do Iguape, Maragogipe (Bahia). Revista Acadêmica Ciências. Agrárias e Ambientais. 2014;12(1):25-34.

37. Ghenghesh KS, Ahmed SF, El-Khalek RA, Al-Gendy A, Klena J. Aeromonas-associated infections in developing countries. Journal Infect Developing Countries. 2008;2(2):81-98.

38. Cereser ND, Rossi Júnior OD, Martineli TM, Souza V, Rodrigues LB, Kerkhoff J. Perfil de resistência de Aeromonas spp. isolada no fluxograma de produção do queijo minas frescal industrial e artesanal. Ars Veterinaria. 2013;29(1):30-36.

39. Jacobs L, Chenia Y. Characterization of integrons and tetracycline resistance determinants in Aeromonas spp. Isolated from South African aquaculture systems. International Journal of Food Microbiology. 2007;114:295-306.

40. Akinyemi KO, Iwalokun BA, Oyefolu AOB, Fakorede CO. Occurrence of extended-spectrum and AmpC $\beta$-lactamases in multiple drug resistant Salmonella isolates from clinical samples in Lagos, Nigeria. Infect Drug Resist. 2017;10:19-25. 